\title{
Dança e Culturas Populares
}

Renata de Sá Gonçalves

Universidade Federal Fluminense

Patrícia Silva Osorio

Universidade Federal de Mato Grosso

Resumo: Apresentamos uma discussão sobre dança e culturas populares. Problematizamos os conceitos de dança e cultura popular, esboçando um breve panorama de seu desenvolvimento nas Ciências Sociais, e particularmente nos estudos antropológicos.

Palavras-chave: culturas populares, dança, antropologia. 


\section{Dance and Popular Culture}

Abstract: This paper presents dance and popular cultures. We discuss the concepts of dance and popular culture, outlining a brief overview of its development in the Social Sciences, and particularly in anthropological studies. Keywords: popular cultures, dance, anthropology.

\section{Danza y Cultura Popular}

Resumen: Este trabajo presenta la danza y las culturas populares. Se discuten los conceptos de la danza y la cultura popular y se esboza la breve descripción de su desarrollo en las Ciencias Sociales, en particular en los estudios antropológicos.

Palabras clave: cultura popular, danza, antropologia. 
Refletir sobre dança e culturas populares não é uma inovação na Antropologia. No entanto, as abordagens sobre danças e culturas populares trazem desafios importantes, especialmente no que toca às pesquisas etnográficas. Um dos desafios passa pela própria discussão acerca dos conceitos de cultura popular e dança. O segundo desafio nos remete ao enfrentamento de questões metodológicas cruciais quando do encontro dos antropólogos com o estudo de formas expressivas que tenham a dança como centralidade.

\section{Problematizando a cultura popular}

Assim como o conceito de cultura, a noção de cultura popular foi muito debatida e criticada. Estamos longe de encontrar homogeneidade nas definições. Há que se mencionar a diversidade de critérios e as divergências quanto à definição de cultura popular, assim como suas aproximações e distanciamentos em relação a outros conceitos. Alguns autores não fazem diferenciação e outros estabelecem separações rígidas entre folclore, cultura popular e ainda, cultura de massa (cf. Carneiro, 1957; Cortazar, 1959; Aretz, 1972; Almeida, 1974). Sem pretender adentrar numa discussão teórica sobre tais noções, faz-se necessário pontuar algumas questões, de modo a articular a centralidade das formas expressivas - especialmente, a dança, neste campo de estudos sobre cultura popular.

O primeiro aspecto a ser ressaltado é o fato de que as noções de cultura popular, folclore e cultura de massa são categorias do nosso pensamento social; integram uma forma de organização social e um modelo civilizatório (Cavalcanti, 2001: 70). São conceitos forjados por uma tradição de estudos datada, que procurava delimitar, caracterizar e nomear práticas que não são (ou eram), necessariamente, designadas pelos seus atores como pertencendo ao rótulo de manifestações folclóricas ou populares (Chaui, 1986; Ortiz, 1992; Chartier, 1995; Cavalcanti, 2001).

Nos termos de Bourdieu (1990), são muitos os usos do “povo”. O campo de estudos da cultura popular é também objeto de disputa e da "lógica da dominação simbólica”. Ao indicar uma relação tensa e dialética entre resistência e submissão dos sujeitos, Bourdieu procura não substantivar o que seria essa “cultura popular", mas os modos de apropriá-la. É preciso, portanto, destacar a ideia de que "o conteúdo de uma disciplina varia historicamente" (Peirano, 1992: 85). Além disso, as disciplinas são hierarquicamente posicionadas, o que 
contribui para que determinados temas sejam mais relevantes em épocas diversas, fazendo com que se aproximem ou se distanciem umas das outras.

O que queremos sublinhar é que

não há qualidades intrínsecas aos fatos de cultura que os façam pertencer naturalmente à cultura popular, à cultura clássica ou à cultura de massas. Há sim conjuntos de questões intelectuais e históricas que se expressam, de modo sintético, nas categorias eleitas para o seu entendimento (Cavalcanti, 1995: 18).

Atualizando a discussão, podemos dizer que o uso do conceito de cultura popular, que aqui colocamos em foco, é o seu uso contemporâneo nativo "para si”. Como problematizado por Manuela Carneiro da Cunha (2009) a cultura sem aspas, em seu sentido conceitual e objetivado, tal como apreendida pela tradição da Antropologia, indica um dos níveis de compreensão da "cultura em si"; e a cultura com aspas, conota o discurso nativo sobre sua própria cultura, ou seja a "cultura para si", que representa uma metalinguagem. Como sabemos, neste último sentido, o termo tem sido acionado por diferentes grupos, principalmente no que toca aos trânsitos estabelecidos com esferas administrativas e setores governamentais ${ }^{1}$. E assim como no discurso antropológico, o uso da noção de cultura popular "na prática" expõe suas vicissitudes, ambivalências e matizes.

De acordo com Roger Chartier (1995) o que importa na identificação de uma manifestação da cultura popular não é a distribuição de certos objetos ou modelos culturais, e sim sua apropriação pelos grupos ou indivíduos. O popular qualifica um modo de utilizar objetos ou normas que são compreendidos e manipulados de diferentes maneiras (: 181). Na atualização de seus fatos culturais os sujeitos articulam noções, valores, referências espaciais e temporais aparentemente paradoxais.

Os estudos sobre cultura popular guardam longa tradição no âmbito das Ciências Sociais. Na Antropologia Brasileira, sua investigação foi utilizada como uma das tentativas de interpretar a sociedade dentro da perspectiva de construção de modelos teóricos para pensar o Brasil, a identidade nacional e a diversidade cultural. A preocupação com a cultura popular teve participação ativa na formação da Antropologia no país, seja no que se refere à demarcação de fronteiras e constituição da disciplina, seja no desenvolvimento teórico, especificamente nas reflexões sobre pensamento social brasileiro, processos identitários, teorias da cultura e antropologia dos rituais ${ }^{2}$. Como identificou Mariza Peirano (1992), houve um distanciamento entre os estudos de folclore e aqueles das ciências sociais, no período entre 1930 e 1980. Isto se deveu, segundo a autora, a uma mudança de eixo onde a Sociologia se ateve às temáticas que envolviam o projeto intelectual de construção nacional. Nesse quadro, a etnografia e o olhar microscópico tinham menos prestígio. Os temas

1Uma reflexão sobre uso local do conceito cultura é feita por Marshall Sahlins (1997) em "O 'pessimismo sentimental' e a experiência etnográfica: por que a cultura não é um 'objeto' em via de extinção”, a partir da pesquisa de Terence Turner sobre os Kayapó.

${ }^{2}$ Aqui lembramos dos estudos pioneiros de Roberto DaMatta $(1973,1979,1981)$ sobre eventos festivos nas décadas de setenta e oitenta. 
folclóricos eram tidos como demasiadamente empíricos, descritivos e desprovidos de um caráter teórico. E nesse sentido, a Antropologia estaria ocupando uma posição pouco apreciada, já que intermediária entre a Sociologia, que se destacava no campo acadêmico, e o Folclore.

Não obstante, as discussões sobre as culturas populares fazem parte da história da antropologia brasileira, tendo contribuído para o desenvolvimento da antropologia dos rituais e para gerar teorias sobre a cultura e processos identitários. Citamos os trabalhos de Elizabeth Travassos (1997), "Mandarins Milagrosos: Arte e etnografia em Mário de Andrade e Béla Bartók”, e Luís Rodolfo Vilhena (1997), "Projeto e Missão: o movimento folclórico brasileiro 1947-1964". Tais obras, ambas publicadas nos anos 90, ao investigarem as diferentes apropriações da noção de cultura popular, trazem à baila complexos jogos entre as tentativas de construção de identidades nacionais e as expressões populares. Ao mesmo tempo fazem emergir uma perspectiva de análise não dicotômica da cultura, construindo esferas de comunicação entre diferentes planos e interesses que constituem a realidade contemporânea.

Atualmente o debate ganha novos elementos com a problematização sobre os processos de profissionalização e patrimonialização das culturas populares. As investigações abordam as mudanças de cenários e contextos nas manifestações da cultura popular a partir das seguintes temáticas: ressignificação e atualização dos folguedos populares (Vianna, 2005; Gonçalves, 2007); processos de espetacularização (Cavalcanti, 2002; Carvalho, 2010), patrimonialização (Sansone, 2012) e profissionalização (Santos, 2009); e as relações entre as práticas culturais populares, o mercado, o turismo e a mídia (Silva, 2012; Osorio, 2012).

Os estudiosos chamam atenção para o modo como diferentes processos atuam nas manifestações da cultura popular em que a utilização dos meios de comunicação de massa, o turismo, a migração e a urbanização geram novas formas de sociabilidades. Além disso, redimensionam (não sem tensões) o debate sobre elementos "modernos" associados a outros "tradicionais". Por outro lado, os autores também alertam para a redução de sentidos e para a emergência de novas sociabilidades vinculadas aos processos de mercantilização das formas culturais.

Para análise da atualização e dos desafios impostos aos grupos de cultura popular na contemporaneidade, as formas expressivas, tais como a dança e a música, colocam-se como instrumentos reflexivos de muita importância, pois atravessam tradições de estudos que se cruzam e nos permitem refletir retrospectivamente e contemporaneamente sobre Folclore, Ciências Sociais, Pensamento Social e Políticas Culturais. Nesta trajetória, fica evidente a forte contribuição dos estudos de folclore que, ainda que imbuídos de um viés romântico e nostálgico, destacaram os múltiplos aspectos expressivos dos folguedos populares, que envolvem dança, música e drama.

Como exemplo desta contribuição, Cavalcanti (2004) realiza uma cuidadosa análise sobre a rica noção de "danças dramáticas" no pensamento de 
Mário de Andrade. Segundo a autora, a expressão "danças dramáticas" foi cunhada, justamente, com o intuito de revelar a unidade subjacente a fatos culturais até então chamados por diferentes nomes. Como desenvolve Cavalcanti, a associação entre música, dança e drama encontrada nessas formas populares parece sugerir solução a um dos problemas críticos da busca estética de Mário de Andrade, o da integração entre arte e vida. Na dança, companheira da música, há expressão artística realizada numa forma plena de vida. Nesse folclore, o corpo humano, expressando-se por inteiro e coletivamente, é ele mesmo o veículo de formas artísticas (Cavalcanti, 2004: 64).

No caso específico da temática aqui tratada, a dança, portanto, coloca em perspectiva o lugar complexo ocupado pelos grupos populares em suas variadas dimensões.

\section{Problematizando a dança}

As reflexões em que a dança se destaca como eixo teórico ou metodológico não são recentes na Antropologia. Autores clássicos como Radcliffe-Brown, Franz Boas, Evans-Pritchard e Margaret Mead fazem menção a essa forma de expressão em publicações datadas respectivamente em 1922, 1927, 1928. Embora mencionada nas análises, a dança ocupou uma posição periférica na teoria antropológica, sendo vista muitas vezes como um tema acessório3.

As reflexões mais sistematizadas - no sentido de pensar os desafios implicados no estudo da dança pelos antropólogos - começam a emergir por volta da década de setenta. A dança (ou o movimento) emerge como um campo de estudos específico em potencial. Ou seja, a dança não se constitui em uma expressão que em decorrência da escolha do objeto de estudo do antropólogo passa a fazer parte de suas preocupações. Ela ganha centralidade teórica e metodológica principalmente em estudos pioneiros produzidos nos Estados Unidos como os de Adrienne Kaeppler (1978) e Joann Kealiinohomoku (1970).

Assim como a noção de cultura popular, o conceito de dança também é submetido a uma problematização. É importante termos claro que dança é uma categoria ocidental4. John Blacking (2013) alerta para o fato de que por mais amplo que seja o conceito de dança, este guarda uma certa dose de etnocentrismo na medida em que é baseado nos conceitos de dança do senso comum, que prevalecem nas culturas euroamericanas.

\footnotetext{
Nós realmente não sabemos o que é "dança”, enquanto fenômeno humano geral. Se, como comportamento ritualizado é um "sistema de modelagem" específico da espécie, poderia ser expresso em outras formas sociais que não aquelas geralmente reconhecidas como dança. Ou poderia ser uma interlinguagem, com a qual as pessoas
}

\footnotetext{
3 Talvez Boas tenha sido uma exceção na medida que ao tratar a "dança primitiva" como uma expressão artística, propunha tratar a arte como um campo autônomo e privilegiado de investigação antropológica.

4 Para uma discussão sobre a questão ver Camargo, 2013.
} 
codificam intenções estratégicas, especificamente, em movimentos que diferem de seus movimentos em contextos de não dança (Blacking, 2013: 75).

Após tal esclarecimento, o autor faz uso da noção, sublinhando sua potencialidade. A dança chama atenção para um modo especial de comunicação que aciona instrumentos não verbais. Isto não significa negar o valor das palavras nas análises sobre dança, muito menos ao reforçar seus aspectos não verbais associar esta forma de expressão às intenções e ações inconscientes. Ainda citando Blacking (2013: 79):

\begin{abstract}
Ao invés de invocar o subconsciente para explicar as experiências de dança e a performance dos padrões de movimento cuja lógica parece desafiar a descrição verbal, mesmo dos participantes, nós deveríamos reconhecer que há linguagens coerentes, estruturadas de dança, e que a transferência do discurso verbal para o não verbal constitui o coração da experiência da dança. Isto não significa que as pessoas abandonam a razão pela emoção quando dançam, mas que elas frequentemente introduzem outro tipo de discurso, cuja gramática e conteúdo são mais efetivamente, mas não exclusivamente, expressos em uma linguagem não verbal.
\end{abstract}

As questões abordadas acima nos informam que para pensarmos a "Antropologia da dança" 5 devemos assumir alguns riscos teóricos e metodológicos. María Julia Carozzi expõe que nosso habitus de classe nos dispõe a registrar, conceituar e analisar os aspectos motores e os verbais da prática de forma separada; e em outras ocasiões nossos entendimentos teóricos promovem sua atenção e tratamento em conjunto. Separamos as atividades educativas, criativas e acadêmicas das atividades de execução (trabalho físico e manual). Como consequência, supomos que as atividades do primeiro tipo são atividades conscientes e as do segundo tipo, não de todo consciente e carentes da palavra (Carozzi, 2011: 12). Há uma divisão histórica que associa a mente à palavra, e o corpo ao movimento. "De tanto hablar sin movernos y de tanto movernos en silencio, tendemos a creer que palabra y movimiento provienen de 'partes' diferenciadas del ser humano"(: 12). A divisão traz consequências tanto para as técnicas de investigação como para as perspectivas que abordam a dança no âmbito da antropologia e das ciências sociais em geral (: 13). Uma das consequências refere-se à tendência de negligenciar a palavra falada e cantada que convive com o movimento nas práticas de dança. Segundo Carozzi, a palavra que aparece nos estudos antropológicos é aquela elucidada nas entrevistas ou a escrita trocada pelos sujeitos de reflexão entre eles e com o antropólogo antes, depois que eles bailam ou que observam outros bailarem (: $32)$.

A dança, embora permeando diferentes sociedades e estando presente nas teorias antropológicas, permanece pouco sistematizada (Gonçalves e Osorio, 2012). Se os estudos sobre cultura popular guardam longa tradição na Antropologia Brasileira, o mesmo não podemos dizer acerca dos estudos sobre dança. Isto não quer dizer que os antropólogos brasileiros não tomem a dança como recorte de pesquisa, ou como perspectiva analítica. Pesquisas etnográficas

5 Ou como preferem alguns pesquisadores, a antropologia dos sistemas estruturados de movimento (Kaeppler, 1985) ou antropologia do movimento humano (Farnell, 1995). 
sobre dança têm sido feitas por vários antropólogos e em diferentes regiões do país (cf. Alves, 2004; Gonçalves, 2010; Veiga, 2011; Salgueiro 2012; Acserald, 2013).

Ainda para indicarmos iniciativas importantes referentes aos estudos sobre dança no Brasil, destacamos a publicação da obra Antropologia da Dança I, organizada por Giselle Guilhon A. Camargo (2013). O livro tem dupla importância: divulgar pesquisas etnográficas e disponibilizar aos leitores brasileiros, traduções de autores caros à antropologia da dança como Blacking, Kaeppler, Youngerman e Kealiinohomoku. Pontuamos também a realização do Grupo de Trabalho "Antropologia da Dança" nas 28 a $29^{a}$ Reunião Brasileira de Antropologia 6 . A proposta do GT foi a de contribuir para a sistematização da antropologia da dança no Brasil, colocando em debate as variadas formas de delimitação desse campo teórico e metodológico. A partir dos estudos propostos, pretendeu-se dar lugar à análise de relações culturais, historicamente e socialmente construídas, estruturadas e inferidas na própria performance; às relações entre estados emocionais, subjetividade, corporeidade; e à dimensão coletiva da dança. Alguns dos trabalhados apresentados na 28 RBA estão reunidos no Dossiê Antropologia da Dança (2012), publicado na Revista Antropolítica da Universidade Federal Fluminense.

\section{Dança e Culturas populares: o dossiê}

O presente dossiê "Dança e Culturas Populares" coloca-se como mais um esforço de divulgação de pesquisas etnográficas que abordem a dança e paralelamente a complexa noção de "cultura popular". Sua proposta é a de compartilhar estratégias e experiências de pesquisa que tenham a relação entre dança e algumas das dimensões contemporâneas das chamadas culturas populares - seja abordando seus aspectos midiáticos, seja suas representações e imagens, de expressão local, nacional e internacional. Ao expor diferentes cenários etnográficos e variadas formas expressivas, o dossiê pretende provocar uma reflexão sobre danças, movimentos e performances.

Indicamos que as diversas perspectivas promovidas e mediadas pelas danças populares acompanham complexos e instigantes modos de lidar com as sociedades, com os sujeitos e seus múltiplos arranjos e planos de significação. É nossa intenção discutir a dança como um dispositivo teórico e metodológico para a abordagem reflexiva sobre as culturas populares nas dinâmicas urbanas, étnicas, etárias, familiares, religiosas e de gênero. Assim pretendemos refletir sobre as relações entre danças populares e estados emocionais, corporeidades, sociabilidades e construções identitárias.

${ }^{6}$ A 28 $8^{\text {a }}$ RBA foi realizada em São entre os dias 02 e 05 de julho. A 29a $\mathrm{RBA}$ ocorreu em Natal entre os dias 03 e 06 de agosto de 2014. 
O artigo "Feminidades a dedo: danças, performances e erotismos no show business brasileiro" de Raphael Bispo, ao focar as populares "chacretes", empreende uma discussão sobre comunicação, performance e gênero. A dança é o ponto de partida do autor para a reflexão sobre a construção do "ser mulher" na sociedade brasileira. Interessante atentarmos para a forma como o autor aciona a dança: esta não apenas expressa, mas constrói, refaz e desfaz as imagens acerca do feminino no Brasil.

Belén Hirose e Lucrecia Greco em "Genealogías performáticas y sujetos populares. Experiencias de danzas folklóricas y populares en Brasil y Argentina", apresentam uma reflexão sobre dança, construção corporal e performance a partir de duas experiências de dança folclórica/popular na Argentina e no Brasil: um ballet de danças folclóricas argentinas e o um grupo de jongo brasileiro. As autoras traçam, a partir de dados etnográficos, uma instigante genealogia acerca dos gêneros performáticos e dos modos como as danças são reconfiguradas por experiências nacionais, assim como pelas respostas dos sujeitos sociais a tais narrativas.

"'¿Cómo crece acá una palmeira de dendé...?": Apropiaciones y resignificaciones de la capoeira en Rosario (Argentina)" de Julia Broguet propõe uma reflexão sobre as representações da capoeira a partir de algumas de suas práticas na cidade de Rosario, Argentina. Broguet indica as representações e imagens construídas na Argentina, propondo uma reflexão sócio-histórica especialmente tendo como base as apropriações e as ressignificações de "modalidades" da capoeira - regional e angola - por jovens da classe média. A autora tem como eixo central a ideia de que o estudo da capoeira na Argentina permite pensar a afirmação identitária e o lugar social da imagem dominante branca e europeia.

Com particularidades teóricas e metodológicas, cada um dos autores trilha seus próprios caminhos na abordagem das danças e das culturas populares. $\mathrm{O}$ que une os artigos aqui apresentados é a tentativa de reforçar a dimensão criativa e expressiva da vida, estabelecendo conexões entre a expressividade dos atos e a compreensão da realidade social. 


\section{Referências Bibliográficas}

ACSERALD, Maria. Viva Pareia! - Corpo, Dança e Brincadeira no CavaloMarinho de Pernambuco. Recife, Ed. UFPE, 2013.

ALMEIDA, Renato. A Inteligência do Folclore. Rio de Janeiro, Companhia Editora América/MEC, 1974.

ALVES, Andréa Moraes. A Dama e o Cavalheiro: um estudo antropológico sobre envelhecimento, gênero e sociabilidade. Rio de Janeiro, Editora FGV, 2004.

ANDRADE, Mário de. Danças dramáticas do Brasil. Belo Horizonte, Itatiaia; Brasília, INL, 1982.

ARETZ, Isabel. Manual del folkore venezolano. Caracas, Monte Avila Editores, 1972.

BLACKING, John. Movimento e Significado: a dança na perspectiva da Antropologia Social. In: CAMARGO, Giselle Guilhon Antunes (org.). Antropologia da Dança I. Florianópolis, Insular, 2013, p. 75-86.

BOAS, Franz. Arte Primitiva. Lisboa, Fenda, 1996.

BOURDIEU, Pierre. Os usos do "povo". In: Coisas ditas. São Paulo, Brasiliense, 1990.

CAMARGO, Giselle Guilhon Antunes. Antropologia da Dança: ensaio bibliográfico. In: CAMARGO, Giselle Guilhon Antunes (org.). Antropologia da Dança I. Florianópolis, Insular, 2013, p. 15-29.

CARNEIRO, Edison. A Sabedoria Popular. Rio de Janeiro, Instituto Nacional do Livro, 1957.

CARNEIRO DA CUNHA, Manuela. Cultura com Aspas. São Paulo, Cosac \& Naify, 2009.

CARVALHO, José Jorge de. 'Espetacularização' e 'canibalização' das culturas populares na América Latina. Revista ANTHROPOLÓGICAS, Recife, UFPE, ano 14, vol.21, 2010, p. 39-76. 
CAROZZI, María Julia. Más allá de los cuerpos móviles: problematizando la relácion entre los aspectos motrices y verbales de la práctica en las antropologías de la danza. In: CAROZZI, María Julia (coord.). Las Palavras y los Pasos: Etnografías de la danza en la ciudad. Buenos Aires, Gorla, 2011, p.745 .

CAVALCANTI, Maria Laura Viveiros de Castro. Carnaval Carioca: dos bastidores ao desfile. Rio de Janeiro, FUNARTE; UFRJ, 1995.

. Cultura e Saber do Povo: uma perspectiva antropológica. Revista Tempo Brasileiro. Rio de Janeiro, n.147, 2001, p. 69-78.

. Os sentidos no espetáculo. Revista de Antropologia. São Paulo, USP, vol. 45, n. 1, 2002, p. 37-78.

- Cultura popular e sensibilidade romântica: as danças dramáticas de Mário de Andrade. Revista Brasileira de Ciências Sociais. São Paulo, vol. 19, n. 54, 2004, p.57-78.

CHARTIER, Roger. "Cultura Popular": revisitando um conceito historiográfico. Estudos Históricos. Rio de Janeiro, vol. 8, n. 16, 1995, p. 179-192.

CHAUI, Marilena. Conformismo e Resistência: aspectos da cultura popular no Brasil. São Paulo, Brasiliense, 1986.

CORTAZAR, Augusto Raúl. Esquema Del Folklore. Buenos Aires, Editorial Columba, 1959.

DaMATTA, Roberto. Ensaios de Antropologia Estrutural. Petrópolis, Vozes, 1973.

- Carnavais, malandros e heróis: Para uma sociologia do dilema brasileiro. Rio de Janeiro, Zahar, 1979.

- Universo do Carnaval: imagens e reflexões. Rio de Janeiro, Pinakotheke, 1981.

EVANS-PRITCHARD, Edward. "The dance". Africa: Jornal of the Internacional African Institute. Cambridge, vol. 1, n. 4, 1928, p. 446-462.

FARNELL, Brenda. Introduction. In: FARNELL, Brenda (ed.). Human Action Signs in Cultural Context: The Visible and the Invisible in Movement and Dance. Metuchen, NJ, Scarecrow Press, 1995, p. 1-28. 
GONÇALVES, Renata de Sá. A dança nobre do carnaval. Rio de Janeiro, Ed. Aeroplano, 2010.

. Os ranchos pedem passagem: o carnaval no Rio de Janeiro do começo do século $X X$. Rio de Janeiro, Secretaria Municipal das Culturas, Coordenadoria de Documentação e Informação Cultural, Gerência de Informação, 2007.

GONÇALVES, Renata de Sá e OSORIO, Patricia Silva. Apresentação: Dossiê Antropologia da Dança. Antropolítica. Niterói, n. 33, 2012, p. 13-23.

KAEPPLER, Adrienne L. Dance in Anthropological Perspective. Annual Review of Anthropology, Vol. 7, 1978, p. 31-49.

- Structured movement systems in Tonga. In: SPENCER, Paul (ed.). Society and the Dance. Cambridge, Cambridge University Press, 1985.

KEALIINOHOMOKU, Joann W. An anthropologist looks at ballet as a form of ethnic dance". In: Impulse 1969-1970: 24-33. San Francisco: Impulse Publications.

MEAD, Margaret. Coming of age in Samoa. New York, HaperCollins, 2001.

ORTIZ, Renato. Românticos e Folcloristas: cultura popular. São Paulo, Olho d'água, 1992.

OSORIO, Patricia Silva. Os Festivais de Cururu e Siriri: mudanças de cenários e contextos na cultura popular. Anuário Antropológico, v. 2011/2012, Brasília, UnB, 2012, p. 237-26o.

PEIRANO, Mariza. "A legitimidade do folclore". In: Seminário Folclore e Cultura Popular: as várias faces de um debate. Rio de Janeiro, IBAC, 1992, p. 85-88.

RADCLIFFE-BROWN, Alfred R. The Andaman Islanders. Glencoe, Illinois, The Free Press, 1948.

SAHLINS, Marshall. O "pessimismo sentimental” e a experiência etnográfica: por que a cultura não é um "objeto" em via de extinção (parte I e II). Mana. Rio de Janeiro, vol. 3, n. 1 e 2, 1997, p. 41-72, p. 103-150.

SANSONE, Livio (org.). Memórias da África: patrimônios, museus e políticas de identidade. Salvador, EDUFBA, ABA Publicações, 2012.

SANTOS, Nilton Silva dos. A arte do efêmero: carnavalescos e mediação 
cultural no Rio de Janeiro. Rio de Janeiro, Apicuri, 2009.

SALGUEIRO, Roberta da Rocha. Um Longo Arabesco: corpo, subjetividade e transnacionalismo a partir da dança do ventre. Tese de Doutorado, Antropologia Social, UnB, 2012.

SILVA, Rubens Alves da. A Atualização de Tradições: Performances $e$ Narrativas Afro-Brasileiras. São Paulo, LCTE Editora, 2012.

TRAVASSOS, Elizabeth. Os Mandarins Milagrosos: Arte e etnografia em Mário de Andrade e Béla Bartók. Rio de Janeiro, Funarte, Jorge Zahar Editor, 1997.

VEIGA, Felipe Berocan. "O Ambiente Exige Respeito": etnografia urbana e memória social da Gafieira Estudantina. Tese de Doutorado, Antropologia, UFF, 2011.

VIANNA, Hermano. Tradição da Mudança: a rede das festas populares brasileiras. Revista do Patrimônio Histórico e Artístico Nacional, n. 32, 2005 , p. 303-315.

VILHENA, Luís Rodolfo. Projeto e Missão: o movimento folclórico brasileiro 1947-1964. Rio de Janeiro, Funarte, Fundação Getúlio Vargas, 1997. 